\title{
Making genomics functional
}

Although biology in the postgenomic era is still grist for Hollywood's science fiction mill-witness such current films as GATTACA, for example-events like the recently completed sequencing of the genome of the human Lyme disease pathogen (Nature 390:580-586, 1997) remind us that it is also happening in the real world right now. Armed with the genome sequences of a variety of organisms-from bacteria to humans-basic and applied biological research will soon be carried out against a landscape unimaginable even to the visionary scientists of the last great biotechnology revolution-gene cloning.

Massive relational databases and computational approaches are taking their places alongside banks of automated sequencers and arrays of biochips as the tools of this new science. And if the pioneers of genetic engineering altered forever the relationship between academic and commercial biology, the effect of genomics is likely to be just as profound. But will knowing the entire human genome sequence change the way in which diseases are diagnosed? Will knowing the correct base order make the analysis of complex phenotypic traits any less daunting than it is right now? Will the finest of genetic maps for a single cell organism, let alone more complex plants, make it easier to engineer desired secondary metabolites in these organisms?

Optimism for the changing landscape of the postgenomic world rests, in part, on the rapid development of new tools and technologies for both producing raw genetic data and for making biological sense of it. If we wish to use the human genome sequence as a blueprint in an expanded program of diagnosis, not only will it be necessary to know which base sequences to identify, but we will have to be able to resequence parts of an individual's genome in a facile and accurate manner. More so, we will only be able to use the same blueprint for clues as to which gene products interact in a "complex phenotypic trait" if we can scan it quickly, accurately, and thoroughly.

Bacteria, though the first self-replicating organisms to be sequenced, present their own special problems when it comes to a functional analysis of their genomes. For example, in order to determine the expression patterns of their nonpolyadenylated messenger RNA under different growth conditions, it is first necessary to devise a way to distinguish it from the much more abundant ribosomal RNA.

Inventions like the DNA chip open up ways of looking at entire gene expression patterns of single cell organisms. The same technology can be sensitive enough to find nonpolyadenylated messages in bacteria. Related approaches are being used to resequence ever larger segments of the genome to detect monogenetic disorders before they manifest a phenotype. The problems of antisense therapeutics are being chipped away, holding out the possibility of drugs to target a disease-causing gene, or its RNA, rather than the final protein product.

Reports of these developments, appearing in this issue-in our feature, review, and research sections-seem a fitting way to inaugurate a new year in which we can expect to see at least some of the tools of functional genomics become truly functional.

\section{Label this science science-free}

A spate of reports has once again propelled agricultural biotechnology products into the spotlight. In one instance, science continues to go by the wayside in the assessment of genetically engineered food plants; in another, a bid for political power has pitted one committee of scientists against another (see news stories on p. 11). In both, the word "science" is evoked to mask the fact that real science has nothing to do with the decisions that are or, perhaps more importantly, are not being made with respect to agricultural biotechnology products in Europe. Unless, of course, we are speaking of the "art and science" of international finance and politics.

Recent biotechnology regulatory processes have been driven by trade agreements such as the General Agreement on Tariffs and Trade (GATT) and the Treaty of Rome and its offspring that established the European Union. Such agreements attempt to realize the economists' dream of the unfettered movement of goods and services between nations. Only on the grounds of safety to humans or the environment can trade flows be interrupted. Nations may invoke essential "sanitary and phytosanitary measures." But the rules reassuringly state that it is only through "science-based" judgments that safety can be assessed.

For protectionists, that "science-based" loophole is readily exploited. Take the recombinant plant products that are trying to come to market in the European Union. Each new plant strain faces at least four scientific committees, two national committees, and two European committees in the areas of environmental and product safety. These attempt to assess product safety by multiplying the probability of adverse events by the magnitude of the possible danger of each event. In almost every case, neither component can be accurately estimated. Virtually all conclusions are speculative. This is science?

Then, on the basis of vague public concerns, the European Novel Foods Regulations demand that foods containing genetically engineered ingredients must be labeled as such. The European Standing Committee on Foodstuffs has been asked for its opinion on the scientific basis of a test for genetically engineered products: Should a test look for protein or should it look for DNA? The role of the scientist in this process has been suborned to answering a contrived and empty question. "Science-based" testing here does not mean rational testing, it just means testing conducted by someone wearing a white coat.

Three maize products-and in all likelihood-all recombinant plant products in the near term-face a further "scientific" hurdle, the Scientific Committee on Plants of DGXXIV, the European Commission's Department of Consumer Health and Consumer Safety. The committee's 15 scientists, drawn for the most part from national governmental laboratories, have yet to produce data or issues that were not already clear from the work of earlier scientific appraisal bodies.

"Science-based" reviews, like those being now being conducted serially in the European Union, obstruct imports and restore trade barriers by popular proxy. They may convince troubled citizens that governments are acting in their best interests. But what they undoubtedly achieve, especially when they are blatantly pointless or speculative, is the undermining of real scientific assessment of benefit and risk. Scientists who want to wage political battle should be free to do so, but they should leave off the mantle of science when they take up the fight. 